\title{
Fatigue in Rapsyn-Deficient Zebrafish Reflects Defective Transmitter Release
}

\author{
Hua Wen, Jeffrey Michael Hubbard, Wei-Chun Wang, and $\odot$ Paul Brehm \\ Oregon Health and Sciences University, Portland, Oregon 97239
}

Rapsyn-deficient myasthenic syndrome is characterized by a weakness in voluntary muscle contraction, a direct consequence of greatly reduced synaptic responses that result from poorly clustered acetylcholine receptors. As with other myasthenic syndromes, the general muscle weakness is also accompanied by use-dependent fatigue. Here, we used paired motor neuron target muscle patch-clamp recordings from a rapsyn-deficient mutant line of zebrafish to explore for the first time the mechanisms causal to fatigue. We find that synaptic responses in mutant fish can follow faithfully low-frequency stimuli despite the reduced amplitude. This is in part helped by a compensatory increase in the number of presynaptic release sites in the mutant fish. In response to high-frequency stimulation, both wild-type and mutant neuromuscular junctions depress to steady-state response levels, but the latter shows exaggerated depression. Analysis of the steady-state transmission revealed that vesicle reloading and release at individual release sites is significantly slower in mutant fish during high-frequency activities. Therefore, reductions in postsynaptic receptor density and compromised presynaptic release collectively serve to reduce synaptic strength to levels that fall below the threshold for muscle action potential generation, thus accounting for use-dependent fatigue. Our findings raise the possibility that defects in motor neuron function may also be at play in other myasthenic syndromes that have been mapped to mutations in muscle-specific proteins.

Key words: myasthenic syndrome; neuromuscular; synaptic depression; synaptic plasticity; variance analysis; zebrafish

Significance Statement

Use-dependent fatigue accompanies many neuromuscular myasthenic syndromes, including muscle rapsyn deficiency. Here, using a rapsyn-deficient line of zebrafish, we performed paired motor neuron target muscle patch-clamp recordings to investigate the mechanisms causal to this phenomenon. Our findings indicate that the reduced postsynaptic receptor density resulting from defective rapsyn contributes to weakness, but is not solely responsible for use-dependent fatigue. Instead, we find unexpected involvement of altered transmitter release from the motor neuron. Specifically, slowed reloading of vesicle release sites leads to augmented synaptic depression during repeated action potentials. Even at moderate stimulus frequencies, the depression levels for evoked synaptic responses fall below the threshold for the generation of muscle action potentials. The associated contraction failures are manifest as use-dependent fatigue.

\section{Introduction}

Human congenital myasthenic syndromes often result from mutations in proteins that are key to synapse development and function. Examples include deficiencies in MuSK (Chevessier et al., 2004; Mihaylova et al., 2009; Maselli et al., 2010), Doc7 (Beeson et

\footnotetext{
Received Feb. 15, 2016; revised Aug. 24, 2016; accepted Sept. 3, 2016.

Author contributions: H.W. and P.B. designed research; H.W., J.M.H., and W.-C.W. performed research; H.W., J.M.H., W.-C.W., and P.B. analyzed data; H.W. and P.B. wrote the paper.

This work was supported by the Muscular Dystrophy Association and the National Institutes of Health (P.B.). We thank James Maylie for advice about offline series resistance compensation and Michael Linhoff for Alexa Fluor 647-conjugated fasll.

The authors declare no competing financial interests.

M. Hubbard's present address: Institut du Cerveau et dela Moelleépinière (ICM) 47, bd del'hôspital, 75013 Paris, France.

Correspondence should be addressed to Paul Brehm, Oregon Health and Sciences University, 3181 S.W. Sam Jackson Park Rd., Portland, OR 97239. E-mail: brehmp@ohsu.edu.

DOI:10.1523/JNEUROSCI.0505-16.2016

Copyright $\odot 2016$ the authors $\quad 0270-6474 / 16 / 3610870-13 \$ 15.00 / 0$
}

al., 2006; Müller et al., 2007; Selcen et al., 2008), agrin (Huzé et al., 2009), acetylcholine receptors (AChR) (Ohno et al., 1997; Engel et al., 2010), and acetylcholinesterase (AChE) (Ohno et al., 1998; Ishigaki et al., 2003). Zebrafish motility mutants have contributed richly to our understanding of many human neuromuscular diseases. For example, mutant lines for AChE (Behra et al., 2002; Downes and Granato, 2004), AChR (Sepich et al., 1998; Ono et al., 2001b), and choline acetyltransferase (Wang et al., 2008) have provided physiological models for myasthenic syndromes. Mutant lines for the P/Q calcium channel (Wen et al., 2013b) and $\alpha$-subunit of the AChR (Walogorsky et al., 2012a; Walogorsky et al., 2012b) also provided new insights into human LambertEaton syndrome and slow channel syndrome, respectively. These lines also served as experimental platforms for testing therapeutic agents that are either currently in use or in clinical trial. Much of this success is due to the ability to perform in vivo paired motor 
neuron target muscle patch-clamp recordings in the vertebrate zebrafish (Wen and Brehm, 2005, 2010). Together with quantitative measurements of swimming performance in zebrafish, it has been possible to link compromised motility to the mechanistic underpinnings.

A phenotypic consequence often shared among the different congenital forms of myasthenic syndromes is fatigue of voluntary movements after exercise (Yasaki et al., 2004). In the case of muscle rapsyn deficiency, the absence of high-density postsynaptic AChRs (Ohno et al., 2002) and the greatly reduced end-plate potentials (EPPs) (Engel, 2007) account for overall muscle weakness. However, this general reduction in amplitude cannot account for the additional fatigue that sets in at moderate- to high-frequency activity. In the present study, we explore for the first time the basis of use-dependent fatigue in an animal model for myasthenic syndrome.

Understanding the mechanisms causal to use-dependent fatigue is challenging because, intuitively, it would seem to point to presynaptic defects such as frequency-dependent synaptic depression. However, whereas mutations in muscle proteins are common among myasthenic syndromes, thus far, none has been reported to affect the function of the motor neuron. Paradoxically, the most common treatment of myasthenic syndromes involves agents that facilitate transmitter release (Engel, 2007), prompting us to revisit a presynaptic contribution to these syndromes. We set out to test directly for presynaptic defects in mediation of use-dependent fatigue using a rapsyn-deficient line of fish, twitch once (two). As with human myasthenic syndrome, these mutant fish exhibit pronounced fatigue (Ono et al., 2001a; Ono et al., 2002). Our studies further exploited the advantages offered by paired motor neuron target skeletal muscle recordings (Wen and Brehm, 2005, 2010), which revealed a compromised speed of reloading and release for active release sites at two motor neurons, resulting in exaggerated synaptic depression and behavioral fatigue. These findings provide the first insights into the mechanisms causal to use-dependent fatigue, a phenotype shared by multiple congenital myasthenic syndromes.

\section{Materials and Methods}

Electrophysiology. Electrophysiological experiments used either wild-type or homozygous two mutant (allele two ${ }^{\text {th26e; }}$; Granato et al., 1996) zebrafish (Danio rerio) of either sex at 72-96 h after fertilization. Paired in vivo electrophysiological recordings between the caudal primary $(\mathrm{CaP})$ motor neuron and target fast skeletal muscle were performed as described previously (Wen and Brehm, 2005, 2010). The CaP soma was held at $-80 \mathrm{mV}$ under current clamp and action potentials were elicited with a $2 \mathrm{~ms}$ current injection. The muscle cells were briefly pretreated with $2 \mathrm{M}$ formamide and held at $-50 \mathrm{mV}$ to help prevent contractions. Muscle miniature end-plate currents (mEPCs) and evoked end-plate currents (EPCs) were sampled at $100 \mathrm{kHz}$ and filtered at $10 \mathrm{kHz}$. Data were acquired with EPC10/2 dual patch-clamp amplifier (List Electronics) under control by HEKA Patchmaster software. Data were analyzed using Igor Pro (WaveMetrics) and Mini-Analysis (SynaptoSoft) and are presented as mean $\pm \mathrm{SD}$ unless otherwise indicated. Statistical comparisons were made with two-tailed $t$ tests in Prism software (GraphPad).

The patch electrodes used for muscle voltage-clamp recordings were low resistance $(2-3 \mathrm{M} \Omega$ ) to minimize the errors associated with series resistance $\left(R_{\mathrm{s}}\right)$. $R_{\mathrm{s}}$ was estimated from the current response to a $10 \mathrm{mV}$ step and monitored throughout the experiment. Experiments were terminated when $R_{\mathrm{s}}$ exceeded $10 \mathrm{M} \Omega$. All synaptic currents were routinely $60 \% R_{\mathrm{s}}$ compensated online, with the remaining $40 \% R_{\mathrm{s}}$ correction performed offline (Traynelis, 1998; Wen et al., 2016). All of the sample traces shown in the figures were $60 \%$ compensated, but all of the tabulated data underwent the additional $40 \%$ offline compensation. Current-clamp recordings from dissociated muscles were performed to determine the rest- ing potential and threshold for the action potential. Muscle cells were dissociated by first removing the larval skin and then incubating the larva in 60\% L-15 + 25 mM Na-HEPES (M-L15; Life Technologies) with $20 \mathrm{mg} / \mathrm{ml}$ collagenase (Life Technologies) for $\sim 90 \mathrm{~min}$ at $28^{\circ} \mathrm{C}$. The larvae were washed in collagenase-free solution and triturated to dissociate individual muscle cells. Recordings were performed within $2 \mathrm{~h}$ of dissociation. Resting potentials were estimated using the initial break in under current clamp and not corrected for liquid junction potential.

Estimation of functional release site numbers. We adopted a multinomial model of release developed by Silver to estimate the number of functional release sites and their release probability. This model describes the relationship between the mean and variance of EPCs, assuming uniform release probability across synapses (Silver et al., 1998; Silver, 2003; Wen et al., 2016).

The mean EPC amplitude $(G)$ and associated coefficient of variation (CV) were determined at a stimulus frequency of $0.2 \mathrm{~Hz}$ for each individual cells. The mean unitary event amplitude $(q)$ and the associated coefficient of variation $\left(\mathrm{CV}_{\mathrm{q}}\right)$ were determined on the basis of asynchronous unitary events during a $100 \mathrm{~Hz}, 20 \mathrm{~s}$ stimulation protocol. $\mathrm{CV}_{\mathrm{q}}$ determined in this way represented the total variability in quantal size. Because the intrasite quantal variability was shown to be very low at this synapse (Wen et al., 2016), $\mathrm{CV}_{\mathrm{q}}$ provided the approximation for intersite quantal variability (Silver et al., 1998; Silver, 2003). The number of functional release sites $(N)$ was then estimated for each recording using Equation 1 (Silver et al., 1998; Silver, 2003):

$$
N=\frac{1}{\left[\frac{q}{G}-\frac{C V^{2}}{1+C V q^{2}}\right]}
$$

The release probability for each release site $\left(P_{\mathrm{r}}\right)$ was next computed according to the binomial model using Equation 2:

$$
P_{r}=G /(N * q)
$$

Recent studies have revealed the contribution of reluctant vesicles to the total releasable pool (Trommershauser et al., 2003; Moulder and Mennerick, 2005). Such kinetic complexity would be expected to affect estimates of $N$ and $P_{\mathrm{r}}$ if distinct vesicle pools are associated with individual release sites. We chose to use the multinomial model because it does not require the additional sorting and trafficking of vesicle populations with different release probability to distinct release sites.

Exocytosis assayed by synaptopHluorin. SynaptopHluorin experiments used two and the paralytic line relaxed (red ${ }^{\text {ts25a; }}$ Granato et al., 1996) that were engineered to express synaptopHluorin in the CaP motor neuron (Wen et al., 2013a). Relaxed was used in the place of wild-type control to avoid small movement artifacts during image acquisition. Live confocal images of fluorescence changes during stimulation were acquired using a Yokogawa CSU-10 spinning disc (Solamere Technologies) with a Stanford Photonics Turbo 620 intensified CCD camera. Sequential images were acquired continuously at $67 \mathrm{~ms}$ intervals using Piper software control version 2.5.04 (Stanford Photonics). Ten image planes were acquired for each time point by quickly displacing the objective (W N-Achroplan $63 \times / 0.9$; Zeiss) in $1 \mu \mathrm{m}$ increments using a piezo device mounted under the objective (Mipos 100; Piezo Systems), which allowed for sampling of many presynaptic terminals (10-20) during the experiment. The $10 \mathrm{im}-$ ages were projected to produce a single image for each time point. Images were analyzed using ImageJ, Microsoft Excel, and custom scripts written in Igor Pro 6.3. To determine the change in fluorescence for individual terminals, regions of interest (ROIs) were placed over responsive presynaptic nerve terminals, as revealed by $100 \mathrm{~Hz}$ stimulation and $50 \mathrm{~mm}$ $\mathrm{NH}_{4} \mathrm{Cl}$ application. An additional five ROIs were placed in adjacent areas that did not contain fluorescence signal to measure local background fluorescence. To correct for background, fluorescence from the five background ROIs were averaged and subtracted from each presynaptic terminal fluorescence. Fluorescence change $(\Delta F)$ was normalized to the baseline fluorescence before the stimulation $\left(F_{0}\right)$ to obtain $\Delta F / F_{0}$. 
A
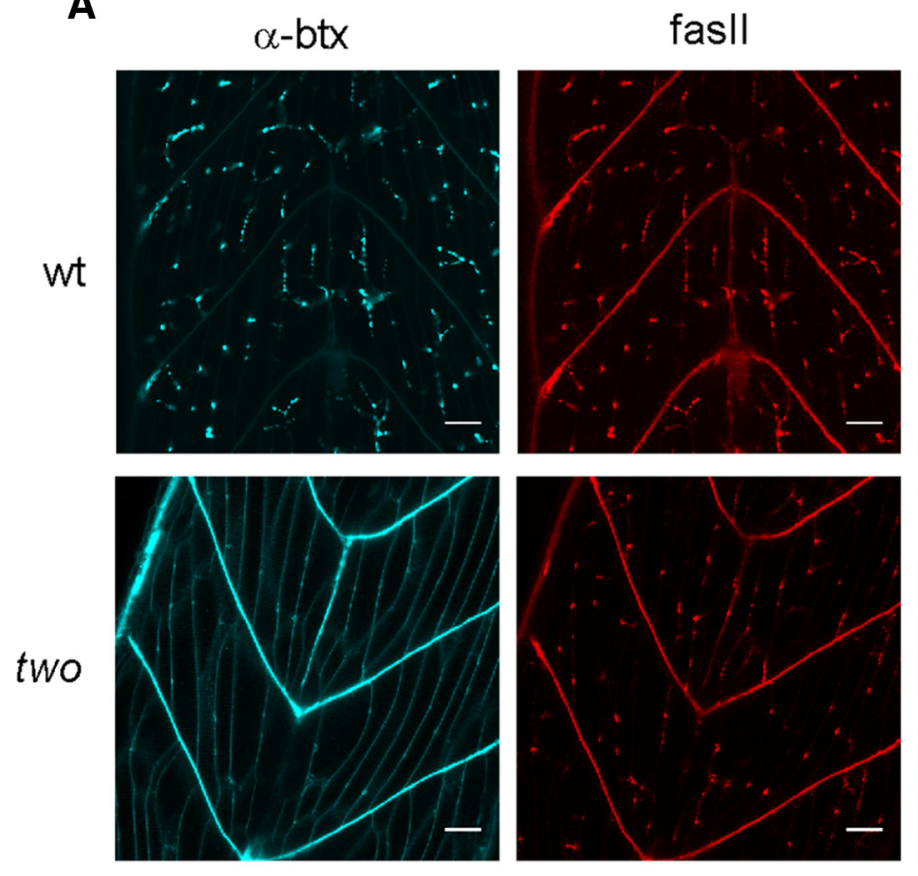

merge
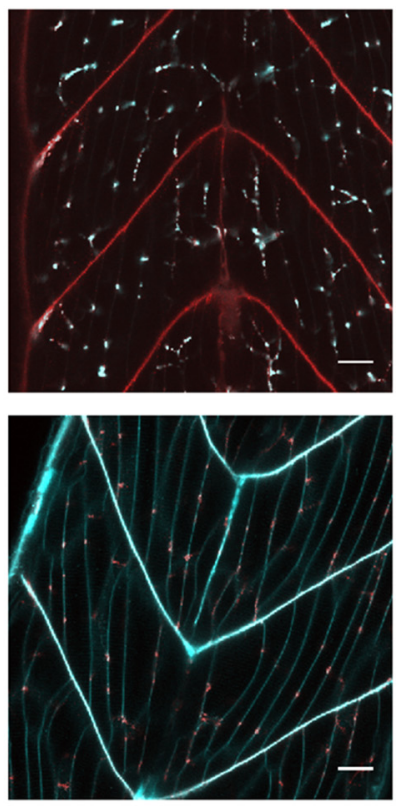

B

Wt

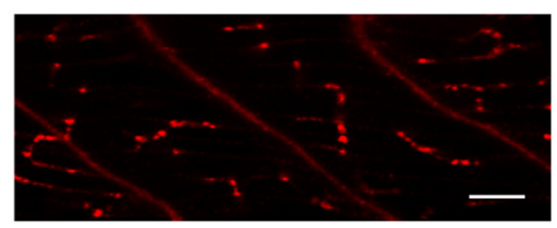

fasll

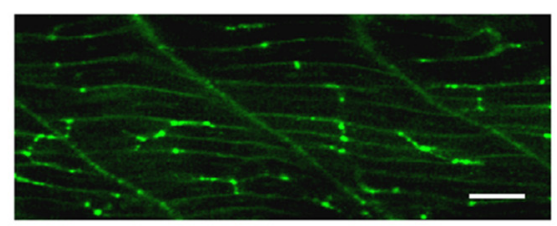

FM1-43

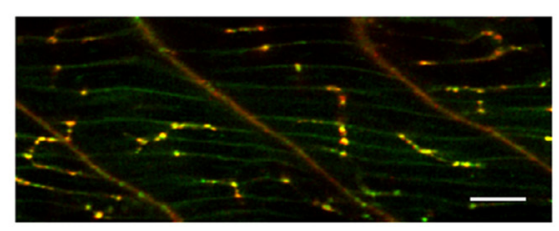

two
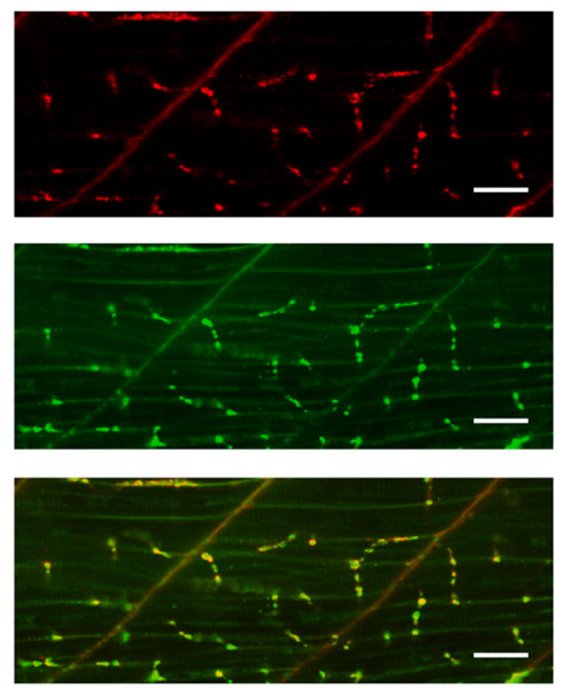

Figure 1. Labeling of AChR, AChE, and synaptic vesicles in wild-type and two fish. A, Images of approximately two segments of wild-type (top) and two (bottom) fast skeletal muscle showing AChR labeling with $\alpha$-btx (left; cyan) and AChE labeling with fasll (middle; red). Merged images (right) show the high incidence of colocalization of the labels in wild-type and the greatly reduced colocalization in two due to the diffuse distribution of AChRs. Fluorescence associated with the septal myocommata represents nonspecific labeling that results from live staining. $\boldsymbol{B}$, Images of two segments of wild-type (left) and two (right) labeled with fasll (top; red) and FM1-43 (middle; green). Colocalization of the labels is shown in the bottom merged image. Scale bar, $20 \mu \mathrm{m}$.

Fluorescence imaging. Fluorescence imaging used an LD C-Apochromat $40 \times$ objective on a Zeiss 710 confocal microscope. AChRs were labeled with Alexa Fluor 555-conjugated $\alpha$-bungarotoxin ( $\alpha$-btx; Life Technologies) and AChE was labeled with fasciculin II (fasII; Alomone Laboratories) that was custom conjugated to Alexa Fluor 647 (Life Technologies). Both labels were microinjected into the bloodstream of live fish 20 min before imaging. Presynaptic terminals were identified by vesicle loading with FM1-43 (Life Technologies) as described previously (Li et al., 2003).

Muscle contraction measurement. Muscle contraction was quantitated on the basis of length change in response to repetitive stimulation of the $\mathrm{CaP}$ motor neuron. The images of fast muscle cells were captured sequentially at 1000 frames/s using a Photonics Fastcam (Photron). The time-dependent changes in muscle length were quantitated frame by frame using Photron high-speed motion analysis tools. Reference points at both ends of a single muscle were chosen to track length change.

\section{Results}

The zebrafish motility mutant two was unable to mount efficient, long-range swimming when stimulated. Instead of the strong initial bend and subsequent rhythmic swimming, two was able to generate only one to a few weak tail flips, reflecting use-dependent fatigue. The skeletal muscle of two was generally healthy in appearance, but labeling with $\alpha$-btx revealed largely diffuse AChRs with only a few small clusters compared with wild-type muscle (Fig. 1A). The compromised clustering of AChRs in two stemmed from a mutation in 
Table 1. Comparison of synaptic transmission properties between wild-type and relaxed zebrafish

\begin{tabular}{llll}
\hline Properties & Wild-type & relaxed & $p$-value \\
\hline $\begin{array}{c}\text { Asynchronous mEPC } \\
\quad \text { amplitude }(\mathrm{pA})\end{array}$ & $1543 \pm 351(n=17)$ & $1411 \pm 313(n=10)$ & 0.34 \\
EPC amplitude $(\mathrm{nA})$ & $18.1 \pm 4.6(n=17)$ & $15.0 \pm 5.4(n=10)$ & 0.13 \\
Quantal content & $12.0 \pm 2.6(n=17)$ & $10.8 \pm 3.4(n=10)$ & 0.31 \\
$\begin{array}{l}\text { 100 Hz steady-state } \\
\quad \text { depression level }\end{array}$ & $0.28 \pm 0.05(n=11)$ & $0.26 \pm 0.03(n=10)$ & 0.31 \\
\hline
\end{tabular}

All data are presented as mean $\pm S D$, with the number of cells indicated in parentheses. None of the properties tested was significantly different at $p=0.05$ (2-tailed $t$ test). The wild-type data were published previously (Wen et al., 2016) and are shown here for comparison with the relaxed data.

rapsyn that led to its retention in the endoplasmic reticulum (Ono et al., 2002; Park et al., 2012). Despite the absence of receptor clusters in two, normal-appearing AChE clusters were identified on the basis of fasII label (Fig. 1A). These AChE clusters marked the site of functional synapses in both wild-type and two based on colocalization of FM1-43-labeled presynaptic vesicles (Fig. 1B). The finding that developmental acquisition of presynaptic function occurred in the absence of postsynaptic receptor clusters is consistent with a previously published study showing that transmitter release occurred in mutant fish lacking AChRs altogether (Li et al., 2003). In that study, however, it was not determined whether quantitative differences existed, which might signal a dependence of exocytosis on postsynaptic receptors.

We set out to explore neuromuscular transmission for defects that account for use-dependent fatigue. As a first step, we investigated whether receptor density or number might affect presynaptic function through use of synaptopHluorin, a sensitive indicator of exocytosis. SynaptopHluorin is formed by a fusion between the $\mathrm{pH}$-dependent GFP and a vesicle-associated membrane protein (VAMP) (Miesenböck et al., 1998). While inside the vesicle, the fluorescence is quenched by the acidic environment, but upon fusion to the plasma membrane, synaptop Hluorin takes on the characteristic GFP fluorescence. Therefore, increases in fluorescence $(\Delta F)$ that accompany stimulation of the motor neuron provide a direct readout of vesicle fusion and associated transmitter release. We created transgenic lines that expressed synaptopHluorin in the terminals of the CaP motor neuron of relaxed and two fish. The relaxed paralytic mutant line was used as the control to eliminate movement artifact associated with muscle contraction during image acquisition. Paralysis results from a mutation in the skeletal muscle dihydropyridine receptor in relaxed, which mediates the excitation-contraction coupling (Ono et al., 2001b; Schredelseker et al., 2005). Therefore, the mutation is far downstream of AChR activation. To insure that the mutation did not affect synaptic transmission, we quantitated the key functional fingerprints for comparison with wild-type fish. No significant differences in mEPC amplitude, EPC amplitude, or quantal content were found using lowfrequency stimulation (Table 1; also see Koyama et al., 2011). In addition, the levels of steady-state depression in response to high-frequency stimulation showed no significant difference between relaxed and wild-type fish, validating its use as the control (Table 1).

Real-time changes in synaptopHluorin fluorescence were measured with a spinning disk confocal microscope. The dim baseline fluorescence allowed selection of optimal image planes containing multiple synaptic terminals (Fig. $2 A$ ). To initiate exocytosis, the CaP motor neuron was stimulated at $100 \mathrm{~Hz}$ for $10 \mathrm{~s}$ to elicit increased fluorescence in the terminals (Fig. 2A). After termination of the stimulus, $50 \mathrm{mM} \mathrm{NH}_{4} \mathrm{Cl}$ was added to neutral- ize the lumen of all remaining vesicles rapidly (Fig. $2 A-C$ ). For both conditions, the change in fluorescence was quantitated as $\Delta F / F_{0}$. This allowed estimation of the fraction of vesicles participating in exocytosis during the $100 \mathrm{~Hz}, 10 \mathrm{~s}$ train, a protocol that leads to nearly complete functional depletion (Wen et al., 2010, 2013a). For each synaptic terminal, the fraction of vesicles released by the stimulus was quantitated as the ratio of fluorescence change associated with stimulus to that associated with $\mathrm{NH}_{4} \mathrm{Cl}$ treatment (Fig. 2D). Stimulus-driven increases in fluorescence were seen for both relaxed and two terminals, but the peak fluorescence levels were significantly smaller for two (Fig. $2 A-C$ ). The reduced level of stimulus-induced release in two was not due to a smaller total vesicle population, as revealed by the maximal fluorescence after the $\mathrm{NH}_{4} \mathrm{Cl}$ treatment (Fig. $2 A-C$ ). Rather, two releases only $14 \pm 10 \%$ of the vesicles compared with $46 \pm 18 \%$ for relaxed fish during the $100 \mathrm{~Hz}$ stimulation (Fig. 2D).

The finding of presynaptic involvement in rapsyn-deficient two fish prompted our further investigation into the causal mechanisms. For this purpose, we turned to paired patch-clamp recordings between the CaP motor neuron and target fast muscle (Wen and Brehm, 2005, 2010). The first measurements compared the unitary mEPCs in wild-type and two fish. Neither the frequency of occurrence (Table 2) nor the decay kinetics of spontaneous mEPCs differed between wild-type and two. However, the amplitudes were greatly reduced in two, reflecting the lowered AChR density (Fig. 3A, Table 2; Ono et al., 2002). Asynchronous unitary events provided an alternative means of estimating $\mathrm{mEPC}$ amplitude. Stimulation of the CaP motor neuron at $100 \mathrm{~Hz}$ for $20 \mathrm{~s}$ led to functional depletion and transition to asynchronous release that corresponded principally to unitary events (Fig. 3B; Wen et al., 2010, 2013a). The high frequency of occurrence permitted large numbers of unitary events to be collected for individual recordings. Both methods produced normally distributed amplitudes in wild-type, but the distribution for two was often right skewed, reflecting the inability to resolve the very small events (Fig. 3C; Wen et al., 2016). Therefore, we only included those two recordings in which a clear peak in the frequency versus amplitude distributions could be resolved. These relations were fit by Gaussian curves with a mean based on the peak value with the right side of the distribution fully resolved. The peak value was then used as the estimate for mean quantal size for two fish. Measurements based on spontaneous events and asynchronous unitary events yielded similar estimates of mean mEPC amplitude, with significantly lower values in all cases for two (Fig. 3D, Table 2).

Having determined the unitary synaptic responses, we turned to measurements of stimulus-evoked EPC amplitudes. Lowfrequency $0.2 \mathrm{~Hz}$ stimulation was used to avoid the complications associated with synaptic depression (Fig. 4A; Wen et al., 2016). As with the unitary event amplitudes, the EPCs in two were significantly smaller than those in wild-type (Fig. $4 A, B$, Table 2). Importantly, the $\sim 15$-fold difference in mean mEPC amplitude between wild-type and two was greater than the $\sim 6$-fold difference in EPC amplitude. As an estimate of quantal content for both two and wild-type, the mean EPC amplitude was divided by the mean mEPC amplitude for each individual recording (Fig. $4 C$; Wen et al., 2016). The quantal content for wild-type ranged from $\sim 7$ to 18 , with an overall average of $12.0 \pm 2.6$ compared with a much wider range of $\sim 7$ to 74 and larger average of $25.9 \pm$ 16.9 for two (Fig. 4C, Table 2).

This $\sim 2$-fold higher quantal content for two could result from either a higher release probability for a similar number of release sites or a larger number of release sites. To distinguish between these possibilities, we used EPC fluctuation analysis to estimate 
A
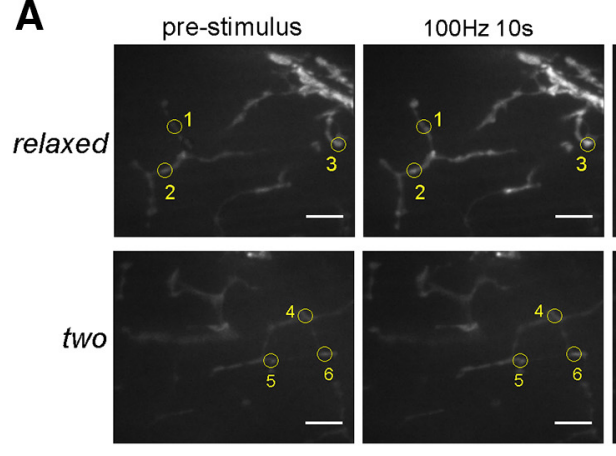

C

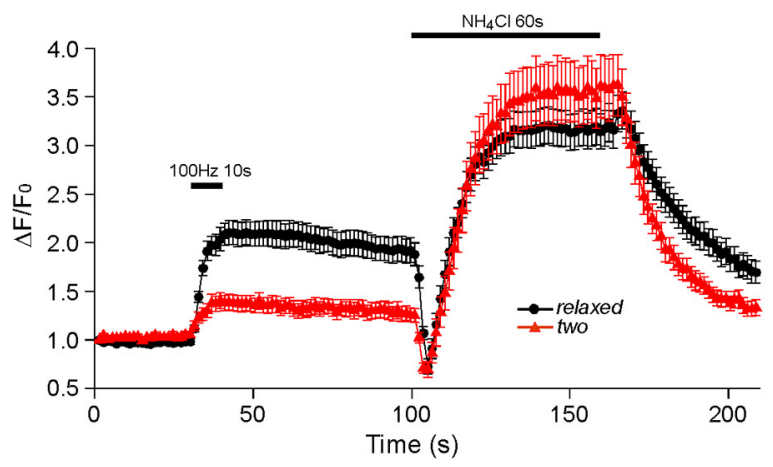

B
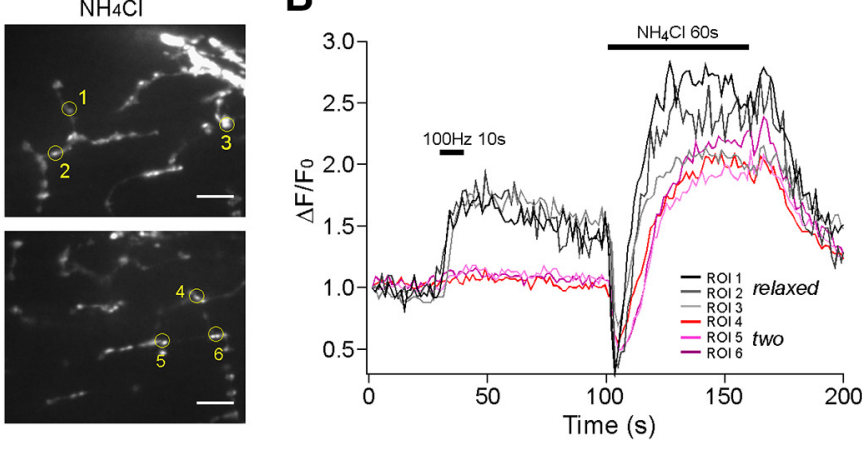

D

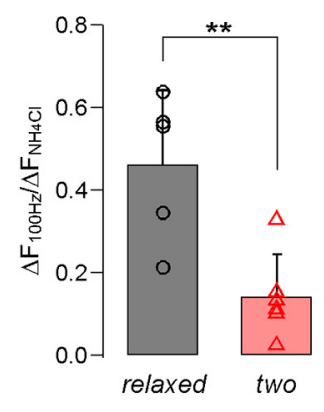

Figure 2. Comparisons of vesicle exocytosis between two and relaxed fish expressing synaptopHluorin in CaP motor neuron terminals. A, Single images of the peak fluorescence signal associated with sample synaptic terminals under prestimulus (left) and poststimulus (middle) conditions. $\mathrm{NH}_{4} \mathrm{Cl}$ was added after the stimulus to reveal total vesicle populations (right). Scale bar, $10 \mu \mathrm{m}$. The paralytic relaxed fish was used in the place of wild-type to avoid movement artifact during image acquisition. $B$, Time course of $\Delta F / F_{0}$ associated with each of the numbered terminals shown in $A$. C, Time course for averaged overall $\Delta F / F_{0}$ measured for relaxed ( $n=69$ terminals from 5 fish) and two ( $n=87$ terminals from 6 fish). Error bars indicate SEM. D, Overall ratios for stimulus-driven fluorescence change to $\mathrm{NH}_{4} \mathrm{Cl}$-induced fluorescence change. Each symbol represents measurement from an individual fish and the overall means $\pm S D$ are shown. ${ }^{* *} p=0.004,2$-tailed $t$ test. The transient decrease seen upon solution change in $\boldsymbol{B}$ and $\boldsymbol{C}$ represents an artifact of unknown origin and was not included in the calculations of steady-state exocytosis.

Table 2. Comparisons of synaptic and membrane properties between wild-type and two zebrafish

\begin{tabular}{|c|c|c|c|}
\hline Properties & Wild-type & two & $p$-value \\
\hline Spontaneous mEPC frequency (events/min) & $17.8 \pm 8.4(n=11)$ & $18.5 \pm 13.7(n=9)$ & 0.9 \\
\hline Spontaneous mEPC amplitude (pA) & $1406 \pm 166(n=11)$ & $85 \pm 7(n=9)$ & $* * * *$ \\
\hline Spontaneous mEPC CV & $0.40 \pm 0.09(n=11)$ & $0.33 \pm 0.05(n=9)$ & 0.05 \\
\hline Asynchronous mEPC CV & $0.35 \pm 0.12(n=17)$ & $0.35 \pm 0.06(n=13)$ & 0.98 \\
\hline EPC amplitude (nA) & $18.1 \pm 4.6(n=17)$ & $2.9 \pm 2.4(n=13)$ & $* * * *$ \\
\hline Quantal content & $12.0 \pm 2.6(n=17)$ & $25.9 \pm 16.9(n=13)$ & ** \\
\hline Paired-pulse ratio; $20 \mathrm{~Hz}$ & $0.72 \pm 0.15(n=8)$ & $0.55 \pm 0.14(n=10)$ & * \\
\hline Paired-pulse ratio; $50 \mathrm{~Hz}$ & $0.78 \pm 0.13(n=7)$ & $0.54 \pm 0.14(n=9)$ & $* *$ \\
\hline Paired-pulse ratio; $100 \mathrm{~Hz}$ & $0.74 \pm 0.05(n=11)$ & $0.52 \pm 0.09(n=13)$ & **** \\
\hline Steady-state depression level; $20 \mathrm{~Hz}$ & $0.33 \pm 0.05(n=8)$ & $0.22 \pm 0.03(n=10)$ & $* * * *$ \\
\hline Steady-state depression level; $50 \mathrm{~Hz}$ & $0.29 \pm 0.04(n=7)$ & $0.18 \pm 0.03(n=9)$ & **** \\
\hline Steady-state depression level; $100 \mathrm{~Hz}$ & $0.28 \pm 0.05(n=11)$ & $0.14 \pm 0.02(n=13)$ & $* * * *$ \\
\hline Reloading rate/site (vesicle/ms); $50 \mathrm{~Hz}$ & $0.014 \pm 0.003(n=7)$ & $0.007 \pm 0.002(n=9)$ & **** \\
\hline Reloading rate/site (vesicle/ms); $100 \mathrm{~Hz}$ & $0.027 \pm 0.005(n=11)$ & $0.012 \pm 0.004(n=13)$ & $* * * *$ \\
\hline Muscle input resistance $(\mathrm{M} \Omega)$ & $397.4 \pm 173.5(n=16)$ & $385.0 \pm 232.4(n=20)$ & 0.86 \\
\hline Muscle membrane capacitance (pF) & $70.4 \pm 13.8(n=16)$ & $70.0 \pm 15.7(n=20)$ & 0.95 \\
\hline Muscle resting potential (mV) & $-62.7 \pm 2.0(n=9)$ & $-64 \pm 3.8(n=11)$ & 0.31 \\
\hline
\end{tabular}

All data are presented as mean $\pm S D$, with the number of cells indicated in parentheses. ${ }^{* * * *} p<0.0001,{ }^{* * *} p<0.001,{ }^{* *} p<0.01,{ }^{*} p<0.05,2$-tailed $t$ test. Part of the wild-type data were published previously $($ Wen et al., 2016) and are shown here for comparison with the two data. 
A

wt

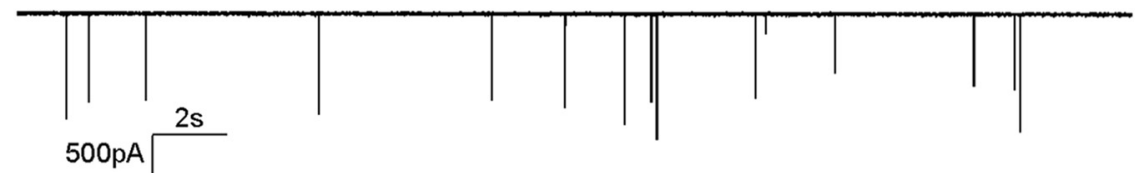

two

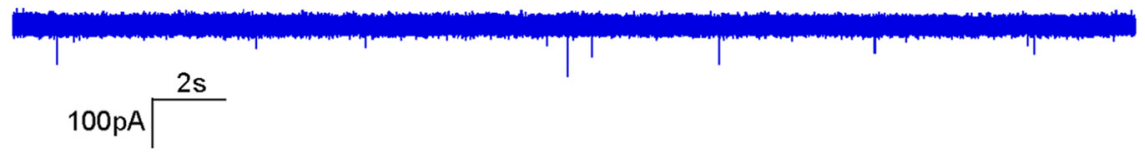

B
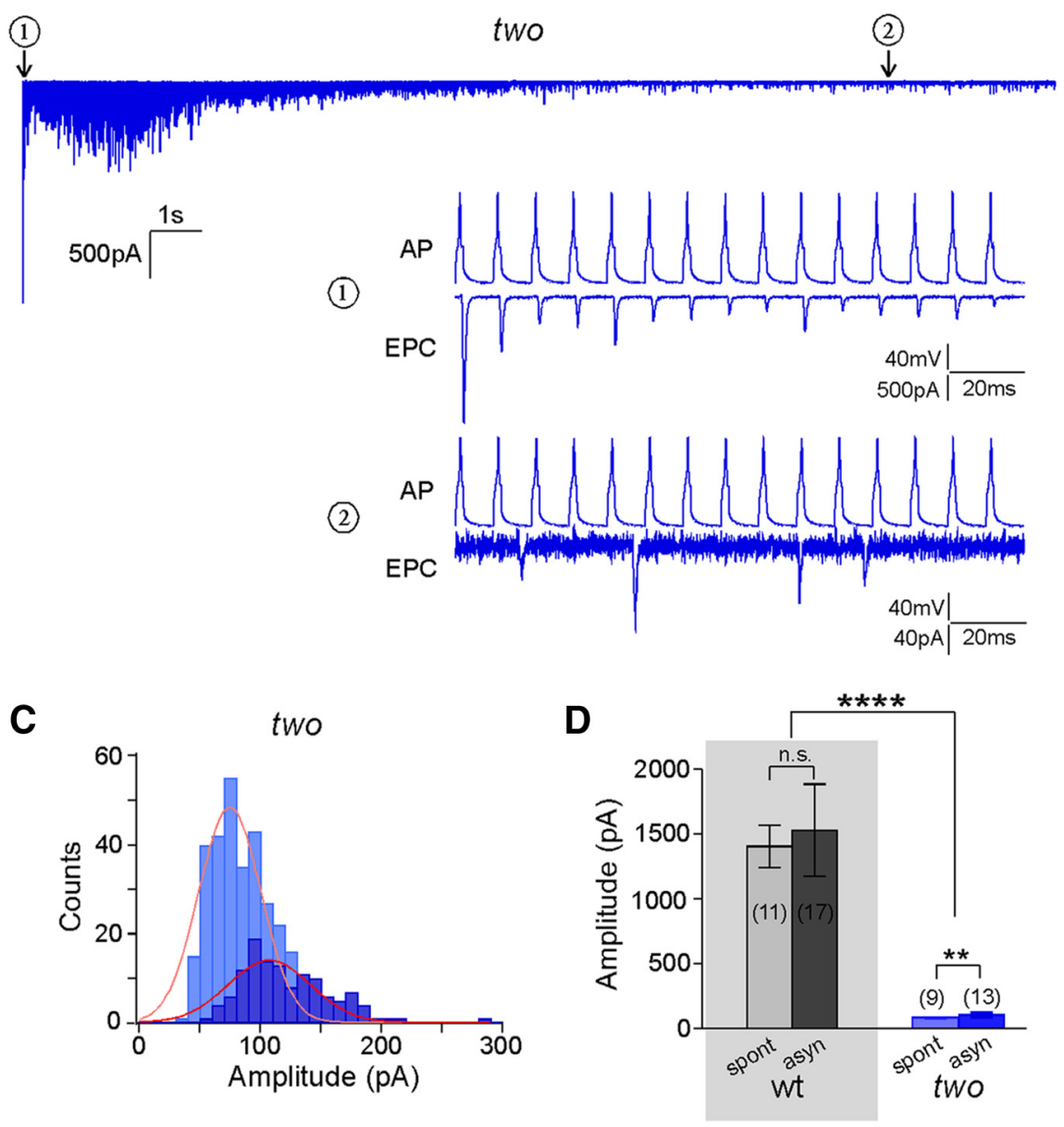

Figure 3. $m E P C S$ are greatly reduced in amplitude in two fast muscle. $\boldsymbol{A}$, Sample spontaneous $m E P($ recordings from wild-type (black) and two (blue) fish. $\boldsymbol{B}$, Sample two recording during a $20 \mathrm{~s}, 100 \mathrm{~Hz}$ train of stimulation showing time-dependent depletion and transition to asynchronous unitary mEPCs. Two magnified regions (indicated by the arrows) show the action potentials (APs) and the associated EPCs, both at the beginning of the stimulus, when release was entirely synchronous (region 1), and late in the train, when asynchronous release dominated (region 2). C, Comparisons of spontaneous (light blue) and asynchronous (dark blue) mEPC amplitude distributions from two, each fitted with a Gaussian curve (red). To obtain a sufficient number of events for generating the spontaneous event amplitude distribution, data were pooled from nine recordings. Sample amplitude distribution for asynchronous unitary events is shown for the example recording in B. D. Summary of mean mEPC amplitudes for all wild-type (gray) and two (blue) recordings determined using spontaneous unitary events (spont) and asynchronous unitary events (asyn). The box indicates wild-type data that were published previously (Wen et al., 2016) and are shown here for comparison with the two data. The overall mean $\pm S D$ is indicated. The number of recordings is indicated in parentheses. ${ }^{* * * *} p<0.0001,{ }^{* *} p<0.01$, n.s.; $p=0.29,2$-tailed $t$ test.

the number of functional release sites $(N)$ and the $P_{\mathrm{r}}$ for each release site (Silver et al., 1998; Silver, 2003; Wen et al., 2016). For this purpose, the mean and variance associated with both $\mathrm{mEPC}$ and EPC amplitude were measured for individual cells, as described above, and a multinomial model of release was applied (see Materials and Methods). Estimates of $N$ for wild-type ranged from 8 to 21 with an average of $13.6 \pm 3.2$, whereas those from two ranged from 16 to 102 with an average of $42.3 \pm 27.6$ (Fig. $4 D$, Table 2). Estimates of $P_{\mathrm{r}}$ ranged from $\sim 0.7$ to 1 with a mean value of $0.9 \pm 0.1$ for wild-type. Estimates for two $P_{\mathrm{r}}$ were lower, ranging from $\sim 0.3$ to 0.9 with a mean value of $0.7 \pm 0.2$ (Fig. $4 E$, Table 2). Therefore, the higher quantal content for two fish resulted from a larger number of release sites, counterbalancing a mild reduction in release probability. 
A higher quantal content for two fish was at odds with impaired exocytosis determined using synaptopHluorin as the optical indicator (Fig. 2). Paired recordings made during bouts of repetitive stimulation that corresponded to rhythmic swimming provided a resolution to this apparent paradox. At stimulus frequencies between 20 and 100 $\mathrm{Hz}$, the EPCs showed a stereotypic depression within the first several responses in both wild-type and two fish (Fig. 5A; Wen et al., 2016). There was no difference in the time course of depression onset at any of the frequencies tested (Fig. 5A). However, the levels of depression achieved after the first few stimuli were significantly greater in two recordings. Comparisons using pairedpulse ratios between the second and the first EPC amplitudes revealed a greater depression for two at 20,50, and $100 \mathrm{~Hz}$ (Table 2). For each recording, the level of steady-state depression was determined on the basis of the mean steady-state amplitude computed for the last 25 EPCs of a train of 30 stimuli divided by the amplitude of the first EPC of the stimulus train. At 20,50, and $100 \mathrm{~Hz}$, the ratios for all recordings were all significantly lower in two, indicating greater synaptic depression (Fig. 5B, Table 2). Therefore, the increased quantal content that was determined at low-frequency stimulation cannot compensate sufficiently for the depression occurring during repetitive stimulation. The exaggerated steady-state depression is consistent with the observed decrease in optically determined exocytosis in two fish (Fig. 2).

Next, we sought to identify the mechanism(s) causal to greater synaptic depression and compromised exocytosis in two. Vesicle availability at the release sites is central to continued release in the face of repetitive stimulation. Both the size of readily releasable vesicle pool (RRP) and the rate at which individual release sites are replenished with new releasable vesicles after prior release could potentially affect the levels of depression (Del Castillo and Katz, 1954; Elmqvist and Quastel, 1965; von Gersdorff and Matthews, 1997; Zucker and Regehr, 2002). We adopted an approach developed for the neuromuscular junction (NMJ) and subsequently applied to central neurons to estimate both parameters (Elmqvist and Quastel, 1965; Schneggenburger et al., 1999; Thanawala and Regehr, 2013; Wen et al., 2016). This method is based on the assumption that the steady-state release is sustained by the balance between vesicle release and replenishment at the release sites. When the cumulative release is plotted versus time, the slope provides a direct measurement of the rate at which release sites are replenished with new vesicles (referred to as reloading rate from here on) and the $y$-intercept approximates the RRP size (Elmqvist and Quastel, 1965; Schneggenburger et al., 1999; Thanawala and Regehr, 2013; Neher, 2015; Wen et al., 2016).

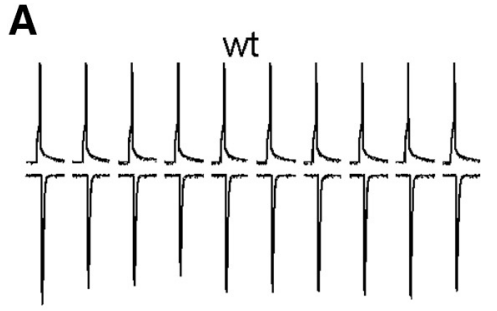

B

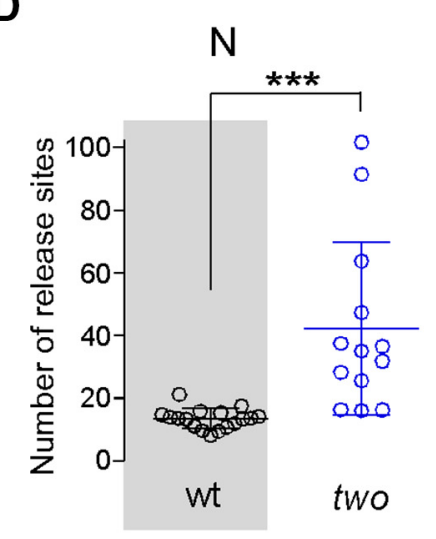

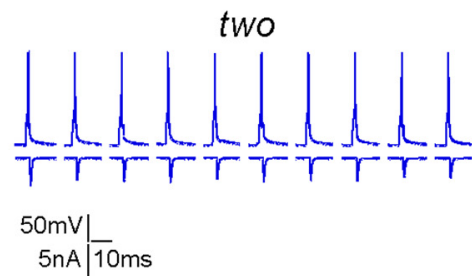

C

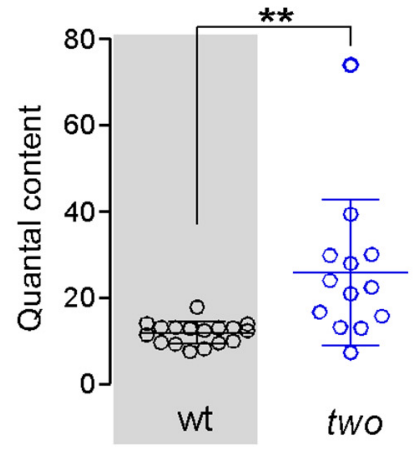

E

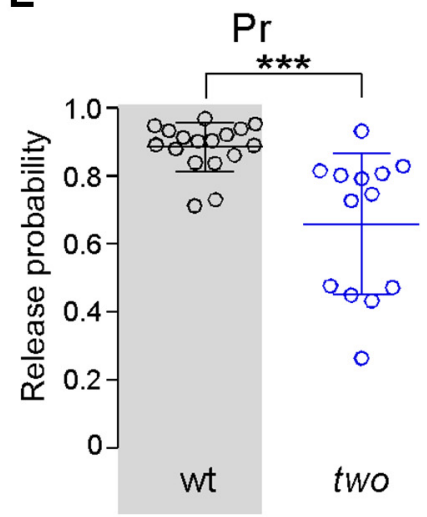

Figure 4. Comparisons of evoked release parameters from wild-type and two fish. $\boldsymbol{A}$, Sample traces of CaP motor neuron action potential (top) and associated EPC (bottom) for wild-type (left; black) and two (right; blue). The stimulus frequency was $0.2 \mathrm{~Hz}$ and individual recordings at $0.2 \mathrm{~Hz}$ for wild-type (black) and two (blue). ${ }^{* * *} p<0.0001$, 2 -tailed $t$ test. $\boldsymbol{C}$, Estimated quantal content number for each recording from wild-type (black) and two (blue). ${ }^{* * *} p<0.001$, 2-tailed $t$ test. $\boldsymbol{E}$, Estimates of release probability for each recording from wild-type (black) and two (blue). ${ }^{* * *} p<0.001$, 2-tailed $t$ test. The shaded area in $\boldsymbol{B}$ - $\boldsymbol{E}$ indicates wild-type data that were published previously (Wen et al., 2016) and are shown here for comparison with the two data.

The CaP was stimulated at $100 \mathrm{~Hz}$ for $300 \mathrm{~ms}$, the peak EPC amplitudes were converted to quantal content, and then the accumulated quantal content was plotted against time during the stimulus train for both wild-type and two fish. Data points corresponding to steady-state responses were fitted using linear regression and back extrapolated to time 0 (Fig. 6A). The $y$-intercept provided an estimate of the size of the RRP available at the onset of stimulation, which corresponded to $19.4-42.5$ vesicles in wild-type versus 19.0-140.4 vesicles for two. This would seemingly point to a larger RRP at two synapses, but the estimated number of release sites was also higher, on average, for two. Moreover, estimates of the RRP and release site number bore a direct relationship for individual recordings (Fig. 6B). Upon correction for differences in release site number, the RRP in two averaged $1.5 \pm 0.5$ vesicles per site at $100 \mathrm{~Hz}$, 
A
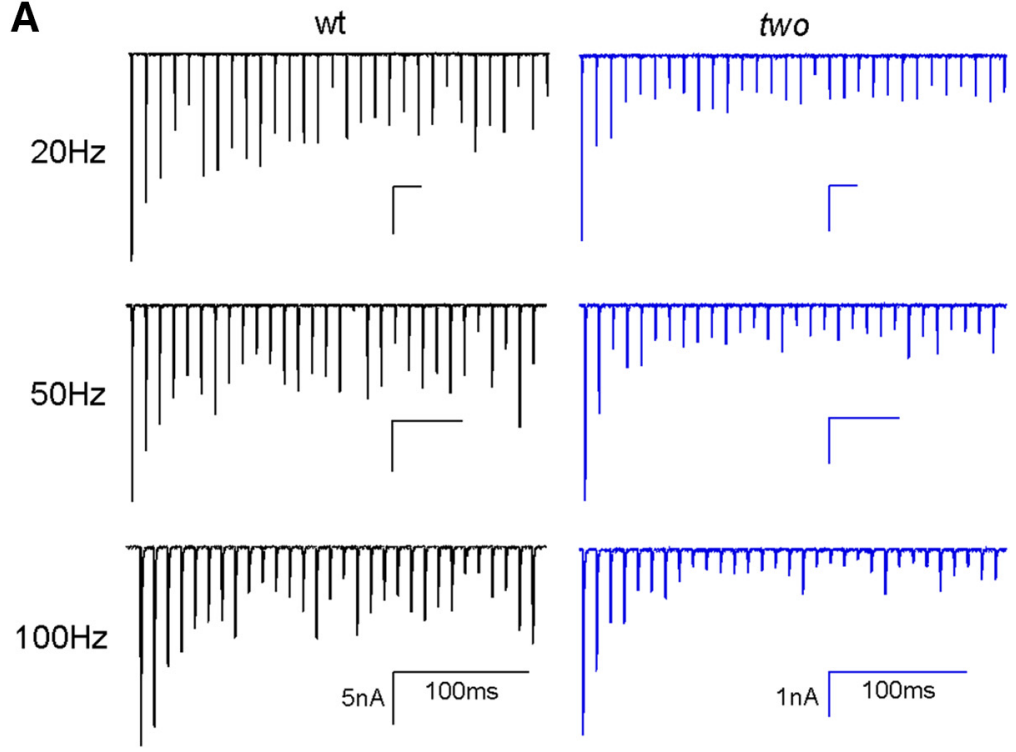

B

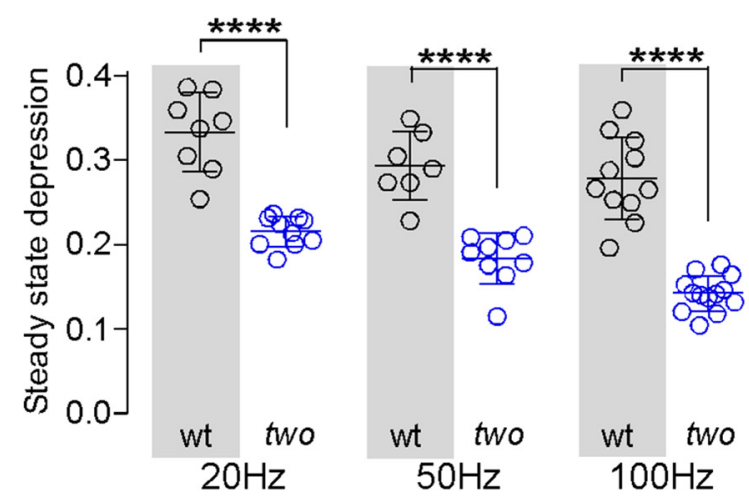

Figure 5. Synaptic depression is greater in two fish. $\boldsymbol{A}$, Sample EPC traces from wild-type (black) and two (blue) fish in response to 30 stimuli delivered at three different frequencies. $\boldsymbol{B}$, Scatter plot of steady-state depression levels for individual recordings from wild-type (black) and two (blue) at the three stimulus frequencies. The steady-state depression for each recording reflects the ratio of average steady-state EPC amplitude to the first EPC. ${ }^{* * *} p<0.0001$, 2-tailed $t$ test. The shaded area indicates wild-type data that were published previously (Wen et al., 2016) and are shown here for comparison with the two data.

which was only slightly smaller than the $2.2 \pm 0.3$ for wild-type (Fig. $6 C$, Table 2). The RRP sizes estimated from 20, 50, and $100 \mathrm{~Hz}$ were similar, suggesting that there was minimal new recruitment of vesicles during the first few EPCs (Fig. 6C). Therefore, the estimates likely represented the entire pool of readily releasable vesicles before stimulation. For both wild-type and two, the pool of one or two readily releasable vesicles would deplete within the first few responses and could not account for the differences in steady-state levels of depression.

The second candidate for conferring differences in steadystate depression level between wild-type and two resided in the reloading rates. The slope of the fitted cumulative release versus time relationship provided an estimate of the number of vesicles reloaded in the whole cell per unit time (Fig. 6A). The slope values were highly variable in $t w o$, but, again, correlated well with the estimated number of release sites for individual cells (Fig. 6D). After correction for differences in release site numbers, the mean reloading rates at each release site for two were significantly slower than wild-type at all frequencies tested (Fig. 6E, Table 2). Two fish reload each site at a rate of 0.012 vesicle/ms at $100 \mathrm{~Hz}$, less than half of the wild-type rate $(0.027$ vesicles $/ \mathrm{ms})$. It took, on average, $83 \mathrm{~ms}$ to equip a release site with a new releasable vesicle in the mutant fish, compared with $37 \mathrm{~ms}$ for wild-type. Therefore, the slower reloading rate for the release sites forms the basis for greater steady-state depression in two fish. The reloading rates for both wild-type and two increased with stimulus frequency (Fig. 6E, Table 2), reflecting calcium-dependent vesicle recruitment, which was greater at shorter interval action potentials (Dittman and Regehr, 1998; Stevens and Wesseling, 1998; Wang and Kaczmarek, 1998; Sakaba and Neher, 2001; Wen et al., 2016). This feature of reloading accounted well for the shallow frequency dependence of depression over the range of 20-100 $\mathrm{Hz}$ (Fig. 5).

Direct measurements of EPC amplitude recovery time course from steadystate levels of depression provided an independent test for slowed reloading in two fish (Fig. 7). For this purpose, a conventional protocol was used wherein the steady-state level of release was established using a $300 \mathrm{~ms}, 100 \mathrm{~Hz}$ train, followed by a single test stimulus delivered at variable intervals after termination of the train (Varela et al., 1997; von Gersdorff et al., 1997; Silver et al., 1998; Wang and Kaczmarek, 1998; Hallermann et al., 2010; McElvain et al., 2015; Fig. 7A). The extent of recovery was measured as the ratio of the test EPC to the first response of the train. The recovery of EPC amplitude followed a biexponential time course in both two (Fig. 7B) and wild-type (Fig. 7B; Wen et al., 2016). The slow time constants for two $(2.81 \mathrm{~s})$ and wild-type $(2.65 \mathrm{~s})$ were similar, but the fast component was significantly slower for two (143.5 ms) compared with wild-type (43.1 ms). Another difference is reflected in the projected fractional recovery curves. The wild-type asymptotically approaches unity whereas the two projects to 0.9 , suggesting the presence of an even slower component of recovery in two. The 3.3-fold slower recovery for $t w o$, specifically in the high-frequency domain, supports the idea that slowed reloading is the principal factor governing enhanced synaptic depression in two fish at high-activity levels such as those involved in swimming behavior.

As a test of the idea that the greater synaptic depression seen in two could contribute to muscle fatigue through action potential failure, we calculated the predicted depolarization associated with consecutive responses for both wild-type and two fish (Fig. $8 A, B)$. For this purpose, we used the amplitudes for each EPCs recorded at $20 \mathrm{~Hz}$ to predict the corresponding EPP amplitudes. Should the EPP fail to reach threshold for a muscle action potential $(-29.4 \pm 3.0 \mathrm{mV}, n=8$ cells $)$, then the muscle would likely fail to contract. The conversion from current to voltage took into account the passive membrane properties through recordings of miniature EPP (mEPP) amplitudes. The mEPPs in wild-type averaged $13.2 \pm 2.0 \mathrm{mV}$ at the resting potential of $-65 \mathrm{mV}(n=6$ cells). The mEPPs could not be fully resolved in two due to their much smaller amplitudes. However, the absence of any differ- 
A

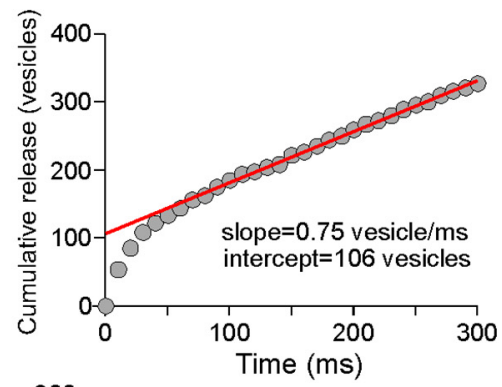

B

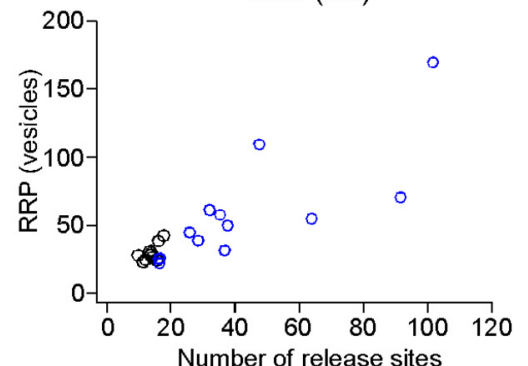

D

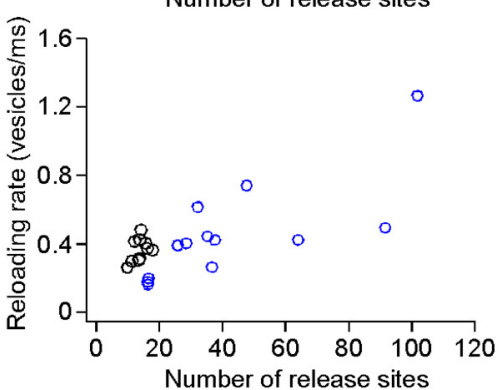

C

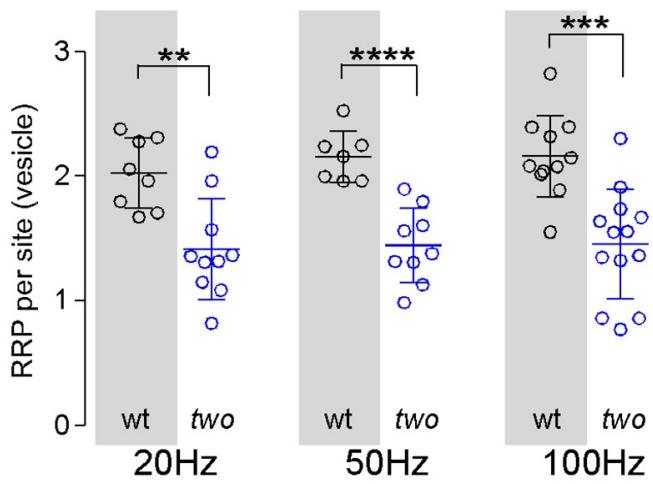

$\mathbf{E}$

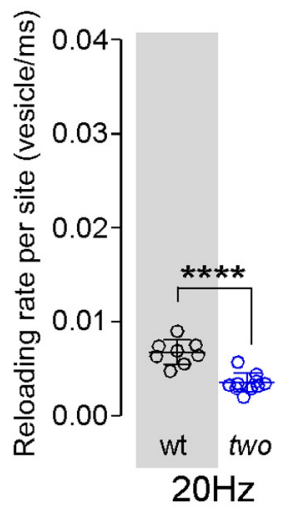

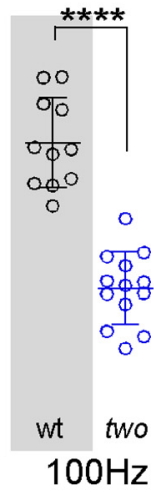

Figure 6. Reloading rates of release sites are reduced in two. $A$, Cumulative release over the $300 \mathrm{~ms}$ stimulation for an example two recording at $100 \mathrm{~Hz}$ as shown in Figure $5 \mathrm{~A}$. Each circle represents a $10 \mathrm{~ms}$ epoch. The release was converted from amplitude to vesicle number on the basis of quantal size for each recording. The red line is a best linear fit for data points in the $60-300 \mathrm{~ms}$ region and back extrapolated to time 0 to intercept with they-axis. The indicated slope and $y$-intercept provided estimates for the reloading rate and the RRP size for the whole cell, respectively. This example two muscle was estimated to have 48 functional release sites. $\boldsymbol{B}$, Scatterplot of RRP versus estimated $N$ for individual muscles from wild-type (black) and two (blue). C, Comparison of RRP estimates per release site for individual wild-type (black) and two (blue) recordings at three stimulus frequencies. ${ }^{* *} p<0.01$, ${ }^{* *} p<0.001,{ }^{* * *} p<0.0001,2$-tailed $t$ test. $D$, Scatterplot of estimated reloading rate versus estimated $N$ for individual muscles from wild-type (black) and two (blue). $\boldsymbol{E}$, Comparisons of reloading rates per release site for individual wild-type (black) and $t w o$ (blue) recordings at three stimulus frequencies. ${ }^{* * *} p<0.0001,2$-tailed $t$ test. The shaded regions in C and $\boldsymbol{E}$ indicate wild-type data that were published previously (Wen et al., 2016) and are shown here for comparison with the two data.

A

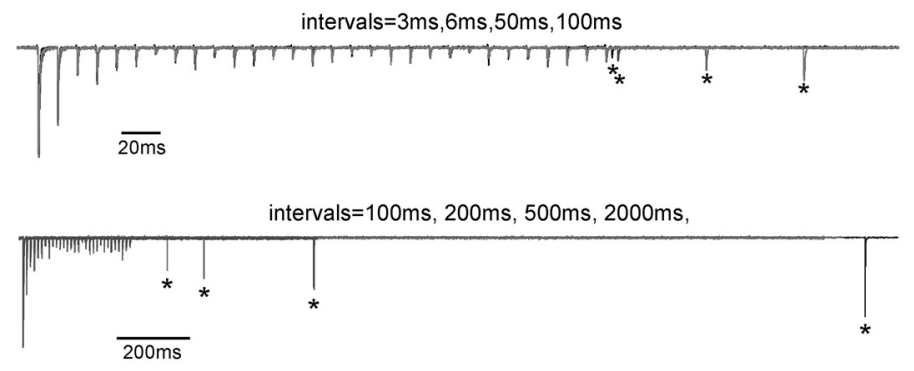

B

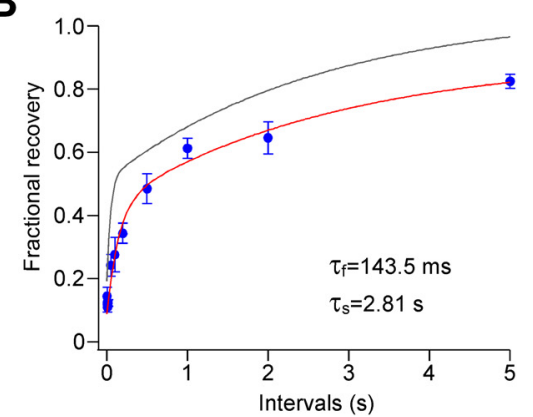

Figure 7. Recovery time course of EPC amplitude after steady-state depression. $A$, Example traces showing recovery of EPC amplitudes after the $100 \mathrm{~Hz}, 300 \mathrm{~ms} \mathrm{stimulus} \mathrm{train.} \mathrm{In} \mathrm{each} \mathrm{trace,} \mathrm{a}$ single test pulse was delivered at variable intervals (designated by asterisks) after termination of the train. Stimulus trains were separated by at least $30 \mathrm{~s}$ resting time to allow full recovery between tests. Traces were normalized to the first EPC of each train and overlaid. Examples for short intervals of 3, 6, 50, and $100 \mathrm{~ms}$ are shown at the top and those for the longer intervals of 100, 200, 500, and $2000 \mathrm{~ms}$ are shown at the bottom. $\boldsymbol{B}$, Recovery time course from steady-state depression for two fish. The mean and SEM for fractional recovery of EPC amplitude is shown for each test interval (blue symbols). The relationship is fit to a biexponential curve (red) with the indicated time constants. Each data point represents the average from $6-15$ cells. The published recovery curve for wild-type is shown in gray for comparison (Wen et al., 2016). Mutant data are significantly different from wild-type for all intervals shorter than $200 \mathrm{~ms}$, and intervals corresponding to 2000 and 5000 $\mathrm{ms}(p=0.05,2$-tailed $t$ test). They are not significantly different from wild-type for intervals 500 and $1000 \mathrm{~ms}$.

ences in passive muscle membrane properties between wild-type and two (resistance, capacitance, and resting potential; Table 2) permitted a means of estimation on the basis of $\mathrm{mEPC}$ amplitude ratios. Using the ratio of mean current amplitudes, the mean
mEPP amplitude for two was $0.9 \mathrm{mV}$. The quantal content for both wild-type and two was then used to predict the EPP amplitude for each of the responses during the $20 \mathrm{~Hz}$ train (Fig. $8 A, B$ ). For wild-type recordings, the average predicted EPP for all 30 
A

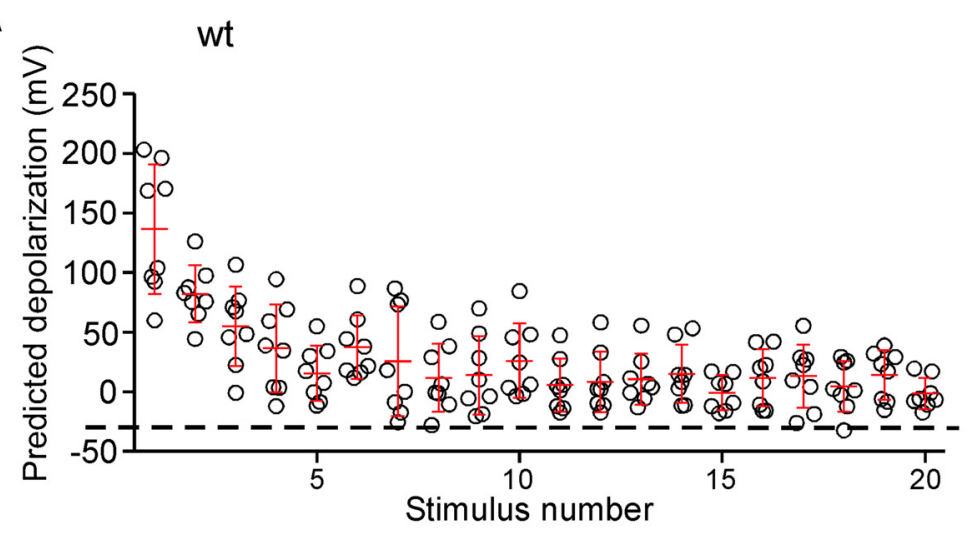

B

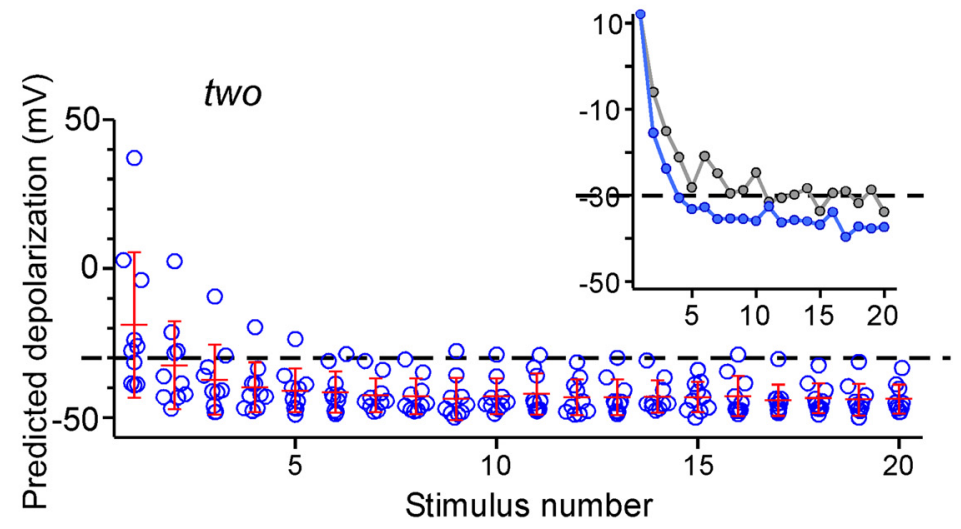

C

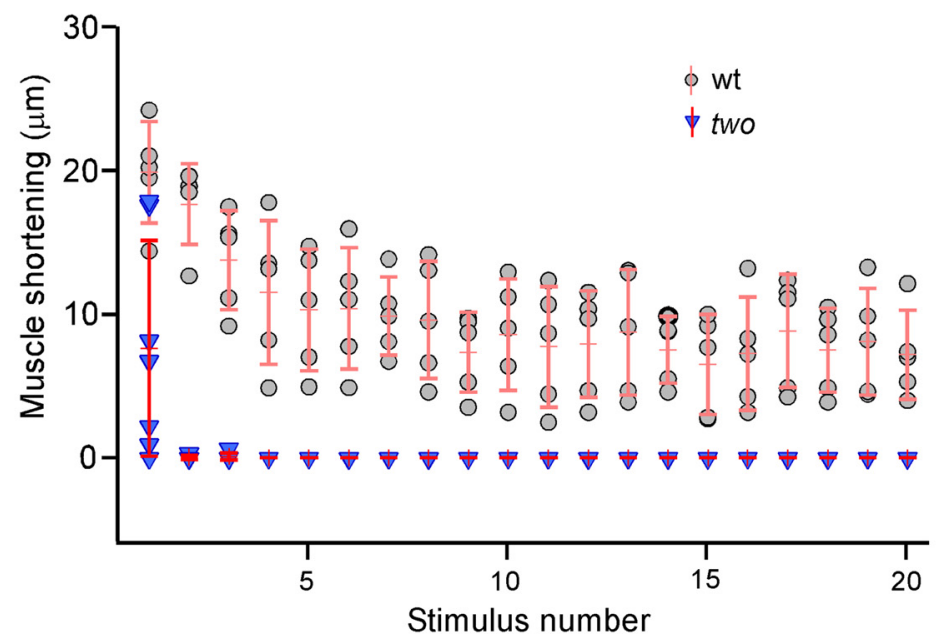

Figure 8. Comparison of the predicted and actual ability to generate contractions during repetitive stimulation for wild-type and two fast muscle. $A$, Predicted levels of muscle depolarization produced by successive EPPs during $20 \mathrm{~Hz}$ stimulation in wild-type $(n=8)$. Each symbol corresponds to the predicted depolarization for individual recordings, with the overall mean and SD indicated in red. Dashed lines indicate the potential corresponding to threshold for a muscle action potential. $\boldsymbol{B}$, Predicted levels of muscle depolarization produced by successive EPPs during $20 \mathrm{~Hz}$ stimulation in two $(n=10)$. Inset shows the average depolarization during $20 \mathrm{~Hz}$ predicted using the wild-type reloading rate (gray) and the two reloading rate (blue) for three two cells that had a high level of compensatory increase in release site number. C, Muscle contraction measured as changes in muscle length in response to successive stimulus during the $20 \mathrm{~Hz}$ stimulation of CaP in wild-type (gray; $n=5$ ) and two (blue; $n=7$ ). Each symbol corresponds to individual recordings, with the overall mean and SD indicated in red.

stimuli exceeded threshold for an action potential (Fig. 8A). However, the predicted values for two, although variable for the first few EPPs, consistently fell below threshold for the subsequent stimuli during the train (Fig. $8 B$ ). It could be argued that the reduced receptor density in two alone could account for the failure to follow high-frequency stimulation without the help of the slower reloading rate. To test for a direct dependence of the differences in reloading rates in placing the steadystate levels subthreshold for action potential generation, we selected the cells with high level of compensatory increase in the number of release sites and estimated EPP amplitude using either the wild-type or two reloading rate (Fig. $8 B$, inset). The predicted levels of EPP would reach threshold for muscle action potentials during $20 \mathrm{~Hz}$ if these cells were reloading the release sites at the rate of wild-type, but fall below threshold using the two reloading rate. Therefore, despite a compensatory increase in release site numbers, the slowed reloading, together with reduced receptor density, drive the levels of depression to subthreshold values.

These predictions were tested directly by measuring contractions in fast muscle during repetitive stimulation of the $\mathrm{CaP}$ motor neuron. Changes in muscle length provided a metric for the ability of muscle cells to follow action potentials generated in the CaP. Fast muscle from wild-type fish was able to contract faithfully to each stimulus up to $100 \mathrm{~Hz}$ (Fig. 8C). However, none of the two muscle cells was able to follow faithfully any frequencies $>1 \mathrm{~Hz}$. Higher-frequency stimulation resulted in contraction failures, usually after the first, but always well within the first few stimuli (Fig. 8C). On these bases, we conclude that the reduced overall EPC amplitude resulting from the combination of lowered receptor density and greater depression are causal to use-dependent fatigue in swimming seen in two.

\section{Discussion}

Although zebrafish are perhaps best known for their contributions to developmental processes, there is much precedent attesting to new insights into vertebrate neuromuscular physiology (Sepich et al., 1998; Ono et al., 2001b; Behra et al., 2002; Downes and Granato, 2004; Wang et al., 2008). This should come as no surprise given the highly conserved structure and function of all vertebrate neuromuscular junctions. To our knowledge, the only evidence for thinking that fundamental differences might exist between mammals and lower vertebrates was the calcium channel isoform mediating neuromuscular transmission. On the basis of pharmacology, frogs were thought to use $N$ types (Sano et al., 1987; Katz et al., 1995; Thaler et al., 2001), as opposed to mammals, which use P/Q type channels (Uchitel et al., 1992). However, we determined recently 
that zebrafish also use P/Q type channels, making it likely that all vertebrate motor neurons use this channel type (Wen et al., 2013b). Zebrafish neuromuscular junction also demonstrated synaptotagmin 7 as the mediator of asynchronous synaptic transmission (Wen et al., 2010), a process first identified at frog neuromuscular junctions (Eccles et al., 1941; Feng, 1941). Subsequently, a role for synaptotagmin 7 in mediating asynchronous release was established for central synapses (Bacaj et al., 2013), further underscoring the importance of zebrafish in revealing general principles of synapse function.

Zebrafish motility mutants have also provided new insights into human diseases such as myasthenic syndromes. In the context of the present study, zebrafish motility mutant two paved the way for identifying rapsyn deficiency as a form of congenital myasthenic syndrome (Ono et al., 2001a; Ohno et al., 2002; Ono et al., 2002; Richard et al., 2003). This human syndrome ranks highly in clinical relevance on the bases of frequency of occurrence and severity (Newsom-Davis, 2005; Lorenzoni et al., 2012). The muscle weakness associated with mutant two fish was ascribed to small-amplitude unitary and evoked synaptic responses resulting from reduced receptor density (Ono et al., 2002). Although reduced synaptic potentials could account for general muscle weakness, they could not fully account for the fatigue associated with repetitive movements in afflicted humans (Ohno et al., 1997; Ohno et al., 2002) and two fish (Ono et al., 2002). Electromyography from humans afflicted with myasthenic syndrome revealed decrementing electrical responses and associated fatigue at frequencies as low as several hertz (Yasaki et al., 2004; Lorenzoni et al., 2012). What was causal to these decrementing responses has remained an open question until now.

In two fish, both optical measurement of exocytosis from the motor neuron terminals and patch-clamp measurements of evoked synaptic currents in muscle indicate compromised transmitter release during repetitive stimulation. The synaptopHluorin experiments indicated a significantly reduced amount of exocytosis in two fish during a $100 \mathrm{~Hz}$ train and paired $\mathrm{CaP}$ motor neuron target muscle recordings indicated significant increases in the levels of steady-state depression. Both results place the locus of dysfunction in the motor neuron, which was unexpected given the locus of postsynaptic mutant rapsyn. The presynaptic defect in transmitter release, together with the greatly reduced receptor density, is causal to postsynaptic depolarizations that fall below threshold for contractions during repetitive activity. This is reflected in our predictions of muscle action potential failures and our direct measurements of muscle shortening during repetitive stimulation. Only at very low frequencies that do not lead to depression can contractions follow motor neuron action potentials faithfully in two fish.

Exploration into the mechanisms causal to the augmented steady-state depression levels in rapsyn-deficient fish pointed to compromised reloading rates for release sites. Unlike some central neurons (Saviane and Silver, 2006), the steady-state transmission at the zebrafish NMJ is not sustained by a large pool of RRP vesicles. Our measurement of the RRP size in both wild-type and two fish yielded estimates of one or two RRP vesicles at each release site, similar to estimates for both mouse calyx of Held and NMJ (Schneggenburger et al., 1999; Ruiz et al., 2011). Therefore, the RRP was depleted in both wild-type and rapsyn mutant fish within the first few stimuli before the establishment of the steadystate transmission. The steady-state levels were determined exclusively by the reloading rate of release sites, which differed significantly between wild-type and mutant fish. When expressed as rate of reloading per release site, the mutant fish were half those of wild-type. Although the bases for this lowered reloading rate is not known, a previous study in wild-type fish might offer potential mechanistic insights (Wen et al., 2016). Both variance analyses and recovery curves for wild-type fish have revealed the coexistence on the individual muscles of two kinetically distinct release sites that are $\sim 60$-fold different in their reloading rates. The fast class followed high-frequency stimulation without failure, whereas a slow class dropped out due to an inability to reload after depletion of the RRP. Therefore, the reloading rate of the fast zones sets the steady-state levels of response during highfrequency stimulation. Our estimates from the recovery time course for the mutant fish also point to the existence of at least two different kinetic components of release. The slow components are similar in wild-type and mutant, but the fast time constant is approximately three times slower, on average, in the mutant. Interpreted in the context of our model, the reloading rates for the fast sites are compromised, which leads to slowed recovery and greater depression.

Altered presynaptic function in response to the muscle rapsyn mutation is not only reflected in the slowed reloading, but also in an increase in the number of release sites. Compensatory increases in transmitter release caused by reduced numbers of postsynaptic receptors have been observed at both fly (Petersen et al., 1997) and mammalian (Plomp et al., 1992) NMJs and are thought to suggest retrograde signaling between the target muscle and the motor neuron. Recordings from intercostal synapse of humans afflicted with myasthenia gravis have also pointed to compensatory increases in quantal content (Cull-Candy et al., 1980). Functional compensation in the form of increased numbers of release sites helped to counter the reduced postsynaptic receptor density in two. Without such compensation, even lowfrequency movements might not be possible. Indeed, in some human cases, the density of AChRs was so low that the associated synaptic potential failed to generate a muscle action potential even at rest (Engel, 2007). We observed that the level of compensatory increases in release site numbers varied widely for two fish. It is important to note that, even in fish with high levels of compensation, the membrane potential would be predicted to fall below threshold for action potential generation due to the slowed reloading rate. Moreover, if the reloading followed the wild-type rate, then these fish would be predicted to sustain movement for moderate frequencies such as $20 \mathrm{~Hz}$ despite the lowered receptor density. This further supports the idea that the slowed reloading rate in two, acting in concert with the reduced postsynaptic receptor density, are causal to the failure to follow high-frequency activity.

Our identification of a potential source of phenotypic variability in motility dysfunction may cast light on rapsyn deficiency in humans. If the same determinants of synaptic function shown here also hold for human myasthenic syndromes, this may help to account for the variability in phenotypic severity (Abicht et al., 2012). There are $>20$ different rapsyn mutations identified to date, all of which are thought, but not shown, to compromise postsynaptic receptor clustering (Hantaï et al., 2004). It is not clear that the different mutations are equivalent in either severity or associated compensation. For example, in afflicted individuals, even the identical mutations are not always a predictor of the phenotypic severity (Maselli et al., 2003; Burke et al., 2004). A rapsyn mutation that leads to a severe phenotype can be asymptotic in another person, pointing to additional factors in the disease state. Our present findings open the door to the idea that 
phenotypic variability among individuals could reflect levels of presynaptic compensation. Furthermore, should the compensation be proportional to the receptor density and associated activity, as suggested by studies on flies (Petersen et al., 1997; DiAntonio et al., 1999), this would potentially explain the phenotypic variability.

A second idea raised by our finding of great variability in compensation between individual recordings relates to the susceptibility of certain muscle groups to dystrophic function in humans (Lorenzoni et al., 2012). The ability of a motor neuron to compensate could depend on either the size of the target muscle field or on the class of motor neuron (Jessell, 2000; Lee and Pfaff, 2001). Should the specific motor neuron type dictate the balance between depression and compensation, it is possible that some affected muscle types would go undetected as a result of increased motor neuron compensation. Therefore, it becomes important to consider motor neuron function as well as target muscle when interpreting the factors causal to synaptic dysfunction.

\section{References}

Abicht A, Dusl M, Gallenmüller C, Guergueltcheva V, Schara U, Della Marina A, Wibbeler E, Almaras S, Mihaylova V, von der Hagen M, Huebner A, Chaouch A, Müller JS, Lochmüller H (2012) Congenital myasthenic syndromes: achievements and limitations of phenotype-guided geneafter-gene sequencing in diagnostic practice: a study of 680 patients. Hum Mutat 33:1474-1484. CrossRef Medline

Bacaj T, Wu D, Yang X, Morishita W, Zhou P, Xu W, Malenka RC, SüdhofTC (2013) Synaptotagmin-1 and synaptotagmin-7 trigger synchronous and asynchronous phases of neurotransmitter release. Neuron 80:947-959. CrossRef Medline

Beeson D, Higuchi O, Palace J, Cossins J, Spearman H, Maxwell S, NewsomDavis J, Burke G, Fawcett P, Motomura M, Müller JS, Lochmüller H, Slater C, Vincent A, Yamanashi Y (2006) Dok-7 mutations underlie a neuromuscular junction synaptopathy. Science 313:1975-1978. CrossRef Medline

Behra M, Cousin X, Bertrand C, Vonesch JL, Biellmann D, Chatonnet A, Strähle U (2002) Acetylcholinesterase is required for neuronal and muscular development in the zebrafish embryo. Nat Neurosci 5:111-118. CrossRef Medline

Burke G, Cossins J, Maxwell S, Robb S, Nicolle M, Vincent A, Newsom-Davis J, Palace J, Beeson D (2004) Distinct phenotypes of congenital acetylcholine receptor deficiency. Neuromuscul Disord 14:356-364. CrossRef Medline

Chevessier F et al. (2004) MUSK, a new target for mutations causing congenital myasthenic syndrome. Hum Mol Genet 13:3229-3240. CrossRef Medline

Cull-Candy SG, Miledi R, Trautmann A, Uchitel OD (1980) On the release of transmitter at normal, myasthenia gravis and myasthenic syndrome affected human end-plates. J Physiol 299:621-638. CrossRef Medline

Del Castillo J, Katz B (1954) Statistical factors involved in neuromuscular facilitation and depression. J Physiol 124:574-585. CrossRef Medline

DiAntonio A, Petersen SA, Heckmann M, Goodman CS (1999) Glutamate receptor expression regulates quantal size and quantal content at the Drosophila neuromuscular junction. J Neurosci 19:3023-3032. Medline

Dittman JS, Regehr WG (1998) Calcium dependence and recovery kinetics of presynaptic depression at the climbing fiber to Purkinje cell synapse. J Neurosci 18:6147-6162. Medline

Downes GB, Granato M (2004) Acetylcholinesterase function is dispensable for sensory neurite growth but is critical for neuromuscular synapse stability. Dev Biol 270:232-245. CrossRef Medline

Eccles JC, Katz B, Kuffler SW (1941) Nature of the endplate potentials in curarized muscle. J Neurophysiol 4:362-387.

Elmqvist D, Quastel DM (1965) A quantitative study of end-plate potentials in isolated human muscle. J Physiol 178:505-529. CrossRef Medline

Engel AG (2007) The therapy of congenital myasthenic syndromes. Neurotherapeutics 4:252-257. CrossRef Medline

Engel AG, Shen XM, Selcen D, Sine SM (2010) What have we learned from the congenital myasthenic syndromes. J Mol Neurosci 40:143-153. CrossRef Medline

Feng TP (1941) Changes in the endplate potential during and after prolonged stimulation. Chin J Physiol 13:29.

Granato M, van Eeden FJ, Schach U, Trowe T, Brand M, Furutani-Seiki M, Haffter P, Hammerschmidt M, Heisenberg CP, Jiang YJ, Kane DA, Kelsh RN, Mullins MC, Odenthal J, Nüsslein-Volhard C (1996) Genes controlling and mediating locomotion behavior of the zebrafish embryo and larva. Development 123:399-413. Medline

Hallermann S, Fejtova A, Schmidt H, Weyhersmüller A, Silver RA, Gundelfinger ED, Eilers J (2010) Bassoon speeds vesicle reloading at a central excitatory synapse. Neuron 68:710-723. CrossRef Medline

Hantaï D, Richard P, Koenig J, Eymard B (2004) Congenital myasthenic syndromes. Curr Opin Neurol 17:539-551. CrossRef Medline

Huzé C et al. (2009) Identification of an agrin mutation that causes congenital myasthenia and affects synapse function. Am J Hum Genet 85:155167. CrossRef Medline

Ishigaki K, Nicolle D, Krejci E, Leroy JP, Koenig J, Fardeau M, Eymard B, Hantaï D (2003) Two novel mutations in the COLQ gene cause endplate acetylcholinesterase deficiency. Neuromuscul Disord 13:236-244. CrossRef Medline

Jessell TM (2000) Neuronal specification in the spinal cord: inductive signals and transcriptional codes. Nat Rev Genet 1:20-29. CrossRef Medline

Katz E, Ferro PA, Cherksey BD, Sugimori M, Llinás R, Uchitel OD (1995) Effects of calcium channel blockers on transmitter release and presynaptic currents at the frog neuromuscular junction. J Physiol 486:695-706. CrossRef Medline

Koyama M, Kinkhabwala A, Satou C, Higashijima S, Fetcho J (2011) Mapping a sensory-motor network onto a structural and functional ground plan in the hindbrain. Proc Natl Acad Sci U S A 108:1170-1175. CrossRef Medline

Lee SK, Pfaff SL (2001) Transcriptional networks regulating neuronal identity in the developing spinal cord. Nat Neurosci 4:1183-1191. CrossRef Medline

Li W, Ono F, Brehm P (2003) Optical measurements of presynaptic release in mutant zebrafish lacking postsynaptic receptors. J Neurosci 23:1046710474. Medline

Lorenzoni PJ, Scola RH, Kay CS, Werneck LC (2012) Congenital myasthenic syndrome: a brief review. Pediatr Neurol 46:141-148. CrossRef Medline

Maselli RA, Dunne V, Pascual-Pascual SI, Bowe C, Agius M, Frank R, Wollmann RL (2003) Rapsyn mutations in myasthenic syndrome due to impaired receptor clustering. Muscle Nerve 28:293-301. CrossRef Medline

Maselli RA, Arredondo J, Cagney O, Ng JJ, Anderson JA, Williams C, Gerke BJ, Soliven B, Wollmann RL (2010) Mutations in MUSK causing congenital myasthenic syndrome impair MuSK-Dok-7 interaction. Hum Mol Genet 19:2370-2379. CrossRef Medline

McElvain LE, Faulstich M, Jeanne JM, Moore JD, du Lac S (2015) Implementation of linear sensory signaling via multiple coordinated mechanisms at central vestibular nerve synapses. Neuron 85:1132-1144. CrossRef Medline

Miesenböck G, De Angelis DA, Rothman JE (1998) Visualizing secretion and synaptic transmission with $\mathrm{pH}$-sensitive green fluorescent proteins. Nature 394:192-195. CrossRef Medline

Mihaylova V, Salih MA, Mukhtar MM, Abuzeid HA, El-Sadig SM, von der Hagen M, Huebner A, Nürnberg G, Abicht A, Müller JS, Lochmüller H, Guergueltcheva V (2009) Refinement of the clinical phenotype in musk-related congenital myasthenic syndromes. Neurology 73:19261928. CrossRef Medline

Moulder KL, Mennerick S (2005) Reluctant vesicles contribute to the total readily releasable pool in glutamatergic hippocampal neurons. J Neurosci 25:3842-3850. CrossRef Medline

Müller JS, et al. (2007) Phenotypical spectrum of DOK7 mutations in congenital myasthenic syndromes. Brain 130:1497-1506. CrossRef Medline

Neher E (2015) Merits and limitations of vesicle pool models in view of heterogeneous populations of synaptic vesicles. Neuron 87:1131-1142. CrossRef Medline

Newsom-Davis J (2005) Neuromuscular junction channelopathies: a brief overview. Acta Neurol Belg 105:181-186. Medline

Ohno K, Quiram PA, Milone M, Wang HL, Harper MC, Pruitt JN 2nd, 
Brengman JM, Pao L, Fischbeck KH, Crawford TO, Sine SM, Engel AG (1997) Congenital myasthenic syndromes due to heteroallelic nonsense/ missense mutations in the acetylcholine receptor epsilon subunit gene: identification and functional characterization of six new mutations. Hum Mol Genet 6:753-766. CrossRef Medline

Ohno K, Brengman J, Tsujino A, Engel AG (1998) Human endplate acetylcholinesterase deficiency caused by mutations in the collagen-like tail subunit (ColQ) of the asymmetric enzyme. Proc Natl Acad Sci U S A 95:9654-9659. CrossRef Medline

Ohno K, Engel AG, Shen XM, Selcen D, Brengman J, Harper CM, Tsujino A, Milone M (2002) Rapsyn mutations in humans cause endplate acetylcholine-receptor deficiency and myasthenic syndrome. Am J Hum Genet 70:875-885. CrossRef Medline

Ono F, Higashijima S, Shcherbatko A, Mandel G, Brehm P (2001a) A mutation in zebrafish rapsyn disrupts ACh receptor clustering and promotes synaptic depression. Soc Neurosci Abstr 27:918.

Ono F, Higashijima S, Shcherbatko A, Fetcho JR, Brehm P (2001b) Paralytic zebrafish lacking acetylcholine receptors fail to localize rapsyn clusters to the synapse. J Neurosci 21:5439-5448. Medline

Ono F, Shcherbatko A, Higashijima S, Mandel G, Brehm P (2002) The Zebrafish motility mutant twitch once reveals new roles for rapsyn in synaptic function. J Neurosci 22:6491-6498. Medline

Park JY, Ikeda H, Ikenaga T, Ono F (2012) Acetylcholine receptors enable the transport of rapsyn from the Golgi complex to the plasma membrane. J Neurosci 32:7356-7363. CrossRef Medline

Petersen SA, Fetter RD, Noordermeer JN, Goodman CS, DiAntonio A (1997) Genetic analysis of glutamate receptors in Drosophila reveals a retrograde signal regulating presynaptic transmitter release. Neuron 19: 1237-1248. CrossRef Medline

Plomp JJ, van Kempen GT, Molenaar PC (1992) Adaptation of quantal content to decreased postsynaptic sensitivity at single endplates in alpha-bungarotoxin-treated rats. J Physiol 458:487-499. CrossRef Medline

Richard P, Gaudon K, Andreux F, Yasaki E, Prioleau C, Bauche S, Barois A, Ioos C, Mayer M, Routon MC, Mokhtari M, Leroy JP, Fournier E, Hainque B, Koenig J, Fardeau M, Eymard B, Hantaï D (2003) Possible founder effect of rapsyn N88K mutation and identification of novel rapsyn mutations in congenital myasthenic syndromes. J Med Genet 40: e81. CrossRef Medline

Ruiz R, Cano R, Casañas JJ, Gaffield MA, Betz WJ, Tabares L (2011) Active zones and the readily releasable pool of synaptic vesicles at the neuromuscular junction of the mouse. J Neurosci 31:2000-2008. CrossRef Medline

Sakaba T, Neher E (2001) Calmodulin mediates rapid recruitment of fastreleasing synaptic vesicles at a calyx-type synapse. Neuron 32:1119-1131. CrossRef Medline

Sano K, Enomoto K, Maeno T (1987) Effects of synthetic $\omega$-conotoxin, a new type calcium antagonist, on frog and mouse neuromuscular transmission. Eur J Pharmacol 141:235-241. CrossRef Medline

Saviane C, Silver RA (2006) Fast vesicle reloading and a large pool sustain high bandwidth transmission at a central synapse. Nature 439:983-987. CrossRef Medline

Schneggenburger R, Meyer AC, Neher E (1999) Released fraction and total size of a pool of immediately available transmitter quanta at a calyx synapse. Neuron 23:399-409. CrossRef Medline

Schredelseker J, Di Biase V, Obermair GJ, Felder ET, Flucher BE, FranziniArmstrong C, Grabner M (2005) The beta la subunit is essential for the assembly of dihydropyridine-receptor arrays in skeletal muscle. Proc Natl Acad Sci U S A 102:17219-17224. CrossRef Medline

Selcen D, Milone M, Shen XM, Harper CM, Stans AA, Wieben ED, Engel AG (2008) Dok-7 myasthenia: phenotypic and molecular genetic studies in 16 patients. Ann Neurol 64:71-87. CrossRef Medline

Sepich DS, Wegner J, O’Shea S, Westerfield M (1998) An altered intron inhibits synthesis of the acetylcholine receptor alpha-subunit in the paralyzed zebrafish mutant nicl. Genetics 148:361-372. Medline

Silver RA (2003) Estimation of nonuniform quantal parameters with multiple-probability fluctuation analysis: theory, application and limitations. J Neurosci Methods 130:127-141. CrossRef Medline

Silver RA, Momiyama A, Cull-Candy SG (1998) Locus of frequencydependent depression identified with multiple-probability fluctuation analysis at rat climbing fibre-Purkinje cell synapses. J Physiol 510:881902. CrossRef Medline

Stevens CF, Wesseling JF (1998) Activity-dependent modulation of the rate at which synaptic vesicles become available to undergo exocytosis. Neuron 21:415-424. CrossRef Medline

Thaler C, Li W, Brehm P (2001) Calcium channel isoforms underlying synaptic transmission at embryonic Xenopus neuromuscular junctions. J Neurosci 21:412-422. Medline

Thanawala MS, Regehr WG (2013) Presynaptic calcium influx controls neurotransmitter release in part by regulating the effective size of the readily releasable pool. J Neurosci 33:4625-4633. CrossRef Medline

Traynelis SF (1998) Software-based correction of single compartment series resistance errors. J Neurosci Methods 86:25-34. CrossRef Medline

Trommershäuser J, Schneggenburger R, Zippelius A, Neher E (2003) Heterogeneous presynaptic release probabilities: functional relevance for short-term plasticity. Biophys J 84:1563-1579. CrossRef Medline

Uchitel OD, Protti DA, Sanchez V, Cherskey BD, Sugimori M, Llinás R (1992) P-type voltage-dependent calcium channel mediates presynaptic calcium influx and transmitter release in mammalian synapses. Proc Natl Acad Sci U S A 89:3330-3333. CrossRef Medline

Varela JA, Sen K, Gibson J, Fost J, Abbott LF, Nelson SB (1997) A quantitative description of short-term plasticity at excitatory synapses in layer $2 / 3$ of rat primary visual cortex. J Neurosci 17:7926-7940. Medline

von Gersdorff H, Matthews G (1997) Depletion and replenishment of vesicle pools at a ribbon-type synaptic terminal. J Neurosci 17:1919-1927. Medline

von Gersdorff H, Schneggenburger R, Weis S, Neher E (1997) Presynaptic depression at a calyx synapse: the small contribution of metabotropic glutamate receptors. J Neurosci 17:8137-8146. Medline

Walogorsky M, Mongeon R, Wen H, Mandel G, Brehm P (2012a) Acetylcholine receptor gating in a zebrafish model for slow-channel syndrome. J Neurosci 32:7941-7948. CrossRef Medline

Walogorsky M, Mongeon R, Wen H, Nelson NR, Urban JM, Ono F, Mandel G, Brehm P (2012b) Zebrafish model for congenital myasthenic syndrome reveals mechanisms causal to developmental recovery. Proc Natl Acad Sci U S A 109:17711-17716. CrossRef Medline

Wang LY, Kaczmarek LK (1998) High-frequency firing helps replenish the readily releasable pool of synaptic vesicles. Nature 394:384-388. CrossRef Medline

Wang M, Wen H, Brehm P (2008) Function of neuromuscular synapses in the zebrafish choline-acetyltransferase mutant bajan. J Neurophysiol 100: 1995-2004. CrossRef Medline

Wen H, Brehm P (2005) Paired motor neuron-muscle recordings in zebrafish test the receptor blockade model for shaping synaptic current. J Neurosci 25:8104-8111. CrossRef Medline

Wen H, Brehm P (2010) Paired patch clamp recordings from motorneuron and target skeletal muscle in zebrafish. J Vis. Exp.

Wen H, Linhoff MW, McGinley MJ, Li GL, Corson GM, Mandel G, Brehm P (2010) Distinct roles for two synaptotagmin isoforms in synchronous and asynchronous transmitter release at zebrafish neuromuscular junction. Proc Natl Acad Sci U S A 107:13906-13911. CrossRef Medline

Wen H, Hubbard JM, Rakela B, Linhoff MW, Mandel G, Brehm P (2013a) Synchronous and asynchronous modes of synaptic transmission utilize different calcium sources. Elife 2:e01206. CrossRef Medline

Wen H, Linhoff MW, Hubbard JM, Nelson NR, Stensland D, Dallman J, Mandel G, Brehm P (2013b) Zebrafish calls for reinterpretation for the roles of $\mathrm{P} / \mathrm{Q}$ calcium channels in neuromuscular transmission. J Neurosci 33:7384-7392. CrossRef Medline

Wen H, McGinley MJ, Mandel G, Brehm P (2016) Nonequivalent release sites govern synaptic depression. Proc Natl Acad Sci U S A 113:E378E386. CrossRef Medline

Yasaki E, Prioleau C, Barbier J, Richard P, Andreux F, Leroy JP, Dartevelle P, Koenig J, Molgó J, Fardeau M, Eymard B, Hantaï D (2004) Electrophysiological and morphological characterization of a case of autosomal recessive congenital myasthenic syndrome with acetylcholine receptor deficiency due to a $\mathrm{N} 88 \mathrm{~K}$ rapsyn homozygous mutation. Neuromuscul Disord 14:24-32. CrossRef Medline

Zucker RS, Regehr WG (2002) Short-term synaptic plasticity. Annu Rev Physiol 64:355-405. CrossRef Medline 